\title{
Mechanism of repetition in transcortical sensory aphasia
}

\author{
MITSUAKI BANDO, YOSHIKAZU UGAWA, MORIHIRO SUGISHITA* \\ From the Department of Neurology, Institute of Brain Research, Faculty of Medicine, Tokyo University, and the \\ Department of Rehabilitation of the Tokyo Metropolitan Institute for Neurological Science, ${ }^{*}$ Tokyo, Japan
}

SUMMARY A typical case of transcortical sensory aphasia (TSA) is presented, in which the Wada के test suggests that it is the right hemisphere which enables the patient to repeat orally. It is supposed $\vec{\circ}$ that one of the mechanisms of preserved repetition in TSA is linked to an exceptional ability for repetition of the right hemisphere, which may help to explain why cases of TSA are so rare.

L. Lichtheim ${ }^{1}$ in 1885 initially outlined the concept of transcortical sensory aphasia (TSA), which includes the following: a TSA patient is unable to understand either written or oral language; however, the patient retains the ability for volitional speech and writing, word repetition, reading aloud, writing to dictation and copying words.

Later, in 1911, Niessl von Mayendorf ${ }^{2}$ proposed four possibilities pertaining to the mechanism for repetition among TSA patients. These possibilities can be summarized in two hypotheses, concerning the disconnection between the sensory centre of speech in the left hemisphere and the other cortical regions, excluding Broca's area. The first hypothesis is that it is the left hemisphere which produces the oral repetition; the second hypothesis is that it is the right hemisphere.

It is the aim of this paper to present a TSA case in which the right hemisphere repeats well. This would support the second hypothesis. Since the right hemisphere manifests an unusual ability for repetition, this could help to explain the relative rarity of TSA cases.

\section{Case report}

The patient was a 65 -year-old, right handed cabman, with an elementary school education, and had no family history of left-handedness or of ambidexterity. On 7 February 1982,

Address for reprint requests: Dr Mitsuaki Bando, Dept of Neurology, Institute of Brain Research, University of Tokyo, 7-3-1 Hongo Bunkyo-ku, Tokyo, Japan.

Received 30 July 1984 and in final revised form 9 July 1985 . Accepted 13 July 1985 he was found to have right hemiparesis, and by the next day? was mumbling incoherently. Although he understood noth- $\overrightarrow{0}$ ing, he was able to repeat the Japanese alphabet. The patient iv had right homonymous hemianopsia, with other cranifili nerves being intact. He also had right hemiparesis witho sensory deficit. Other neurological findings were normal. $\emptyset^{2}$ 윽 23 April 1982 computed tomography of the head revealec $\mathbb{B}_{2}-$ left large parieto-temporal low density area (fig). Left cat otid angiography showed a stem occlusion of the left midd fe $\frac{\mathbb{D}}{D}$ cerebral artery, though a few branches in the anterior part $\varnothing f$ its territory were filled. The left anterior cerebral artery was intact. The right anterior cerebral artery was intact. Rigit carotid angiography revealed no arterial occlusion or ce्t- $\overrightarrow{0}$ lateral artery perfusing the left hemisphere.

Neuropsychological studies

The patient has been repeatedly reexamined. His speech pattern has remained essentially unchanged for the past two years.

\section{A Language}

I Volitional speech The patient's volitional speech was음 poor. He rarely spoke without first being spoken to. $\mathrm{He}^{\exists}$ could say short grammatical sentences such as "I am all right" or "I cannot understand," as well as all the numbers? from one to ten and the Japanese alphabet. He was also able to reply with a short sentence to a simple question, but only? when the contextual situation was obvious. The patient's speech was fluent and without grammatical errors or jargon. 3 . But he showed marked literal paraphasia in naming objects. 2 Oral comprehension The patient's oral comprehension $\frac{0}{3}$ was completely obliterated. Even when called by the' wrong name, he mistook it for his own. He could not execute verbal음 commands, and showed no reaction to absurd questions. 3 Reading ability On 13 August 1982, the patient was음 able to read out aloud six out of 48 ideograms, five out of $48 \mathrm{~N}$ phonograms and eight out of 10 Arabic names, showing a 

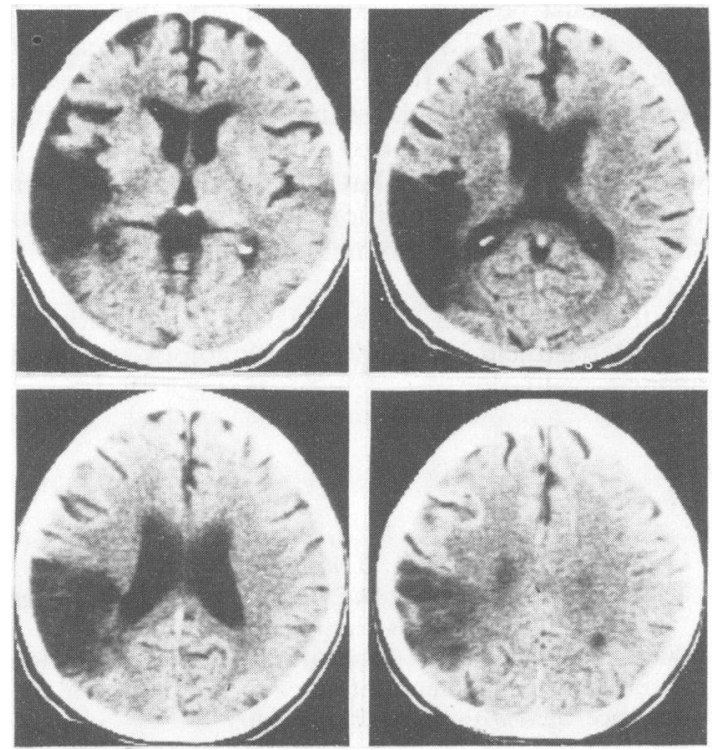

Fig Computed tomographic scans showing a large left parieto-temporal lesion.

better reading ability than oral. Types of error most often committed by the patient were paraphasia and perseveration. He pointed correctly to four out of six objects whose names were written with ideograms, and two out of six phonograms. However, he never responded to any written command nor answered written alternative questions correctly.

4 Writing ability The patient could not write or copy any letters of the alphabet, and it was rare for him to write his own or other personal names spontaneously.

5 Repetition ability The patient's repetition ability was quite good, though he showed little echolalia and limited ability to complete proverbs. When one sang the first few phrases of his favourite popular songs, he sang along with the exact melody and words.

To estimate his ability to repeat quantitatively, eight series of digits, presented at the rate of two digits per second, were used. Upon each examination, he could repeat six digits completely; sometimes up to seven digits mingled with paraphasic errors. In the subtest of the Auditory Sequential Memory of Illinois Test of Psycho-linguistic Abilities (ITPA), he scored 39 points. He was able to repeat eight series of eight nonsense syllables accurately, and could repeat four of eight series of nine syllables.

The scores from the Western Aphasia Battery, about one and a half years after the first examination are shown in the table.

\section{$B$ Praxis and gnosis}

The patient had severe apraxia, but no gross abnormality of recognition.

\section{Other examinations}

Pure tone audiogram was obtained on 19 April 1982. The patient's average hearing loss was only $3.75 \mathrm{~dB}$ for the right
Table Scores of WAB's subtests

Information content

Fluency

Yes-no questions

Auditory word recognition

Sequential commands

Comprehension total

Repetition

Object naming

Word fluency

Sentence completion

Responsive speech

Naming total

Aphasia Quotient

Reading

Writing

Praxis

Drawing

Block design

Calculation

Raven's Colored Progressive Matrices

ear, and $0 \mathrm{~dB}$ for the left. However, with speech audiometry, the Speech Discrimination Rate (SDR) was $65 \%$ for the right ear, and $95 \%$ for the left, suggesting damage to the left temporal lobe. Speech Receptive Threshold was $25 \mathrm{~dB}$ for the right ear, and $20 \mathrm{~dB}$ for the left. As there was hearing loss of the right ear for speech sounds, it was impossible to decide the laterality of the site of repetition with the Dichotic Listening Test.

\section{Wada Test}

After informing the patient's family and with their consent, the Wada test was given during the angiography. Following the Wada and Rasmussen ${ }^{3}$ procedure as modified by Sento ${ }^{4}$ for the Japanese, two intracarotid injections to the right and left, of dosage $100 \mathrm{mg}$ amylobarbital in $10 \%$ solution were given to the patient. At both trials of injections, the effect of amylobarbital was ascertained by dropping of the arm on the respective contralateral side. Before each injection, the patient was able to repeat eight series of four digits and of eight syllables. The right-sided injection was given first. For at least 5 minutes following the injection, the patient stopped repeating digits or words. After a certain interval in which his repetition ability was recovered, the left-sided injection was given. Immediately following the injection, the patient was able to repeat four digits perfectly; repetition of eight syllables and six digits was also possible. These results suggest that the patient's right hemisphere has a remarkable ability of repetition, whereas his left hemisphere does not.

\section{Discussion}

Given Lichtheim's definition of TSA as characterised by fluent spontaneous speech, complete loss of oral comprehension and almost intact ability of repetition, the above described case, with the exception of the writing disability and the relatively moderate disability of reading aloud, is a typical case of TSA. That such a typical case is regarded as extremely rare is proven by the fact that Wernicke, ${ }^{5}$ the originator of the term of transcortical aphasia, along with many other writers doubted its existence. 
Niessl von Mayendorf, ${ }^{2}$ upon review of the available literature on TSA, (Goldstein ${ }^{6}$ was to later discuss the same cases) proposed two hypotheses concerning the mechanism of the disorder. The first is that there is a disconnection between the "Wortklangbildzentrum" (centre of sound images of words)" in the left hemisphere and the other cortical regions where the "Vorstellungen" (representations) lie. Because the connection between the centre of sound images of words and the motor centre of speech is preserved, repetition is possible. In this hypothesis, it is the left hemisphere which repeats orally. The second hypothesis is that the right hemisphere executes repetition without comprehension because it does not have abundant association with the other cortical regions, namely, "Begriffszentrum" (centre of concept) as the left hemisphere does. Niessl von Mayendorf really had some grounds for this second hypothesis in that the left speech area was found to be completely destroyed in some cases of TSA upon necropsy. The result of the Wada test in our case strongly adds support for the second hypothesis in that the patient's right hemisphere enables oral repetition, rather than the left.

In view of the fact that almost all other cases with severe damage of the left hemisphere (with an intact right hemisphere) were not able to repeat as well as in our case, the facility of repetition by the right hemi- sphere must be quite exceptional. And this may be one reason why TSA is so rare. As the patient was able to repeat well from a relatively early stage of observation, we could assume that his right hemisphere had this ability prior to the onset of aphasia. It was shown in this case that it is the right hemisphere which enables oral repetition. Whether this is true for all other cases of TSA remains to be determined.

We thank Kimitaka Kaga M.D., of Teikyo University, Department of Otorhinolaryngology, for audiometric evaluation.

\section{References}

${ }^{1}$ Lichtheim L. On aphasia. Brain 1885;7:433-84.

${ }^{2}$ Niessl V, Mayendorf E. Die Aphasischen Störungen und ihre Kortikale. Lokalisation. Leipzig: Barth, 1911.

${ }^{3}$ Wada $\mathrm{J}$, Rasmussen $\mathrm{T}$. Intracarotid injection of sodium amytal for the lateralization of cerebral speech dominance. $J$ Neurosurg 1960;17:266-82.

${ }^{4}$ Sento S. A study on clinical application of intracarotid amobarbital injection. (Japanese). Journal of Tokyo Women's Medical College 1974;44:382-412.

${ }^{5}$ Wernicke C. Der aphasische Symptomenkomplex. Deu- iv tsche Klinik 1906;VI Abth 1:487-556.

${ }^{6}$ Goldstein K. Die transkortikalen Aphasien. Ergebn de Neurol Psychiatr 1917;II. 